\title{
The Influence of the Pharmacists' Training on the Patients' Education in the Field of Inhalation Techniques in Community Pharmacies in Poland
}

\author{
Magdalena Waszyk-Nowaczyk ( $\sim$ mwaszyk@ump.edu.pl ) \\ Poznan University of Medical Sciences \\ Patrycja Targosz \\ Poznan University of Medical Sciences \\ Weronika Guzenda \\ Poznan University of Medical Sciences \\ Michał Byliniak \\ Polish Pharmaceutical Chamber

\section{Beata Plewka} \\ Poznan University of Medical Sciences \\ Piotr Dąbrowiecki \\ Wojskowy Instytut Medyczny \\ Michał Michalak \\ Poznan University of Medical Sciences \\ Aneta Bąbol \\ Lindsay \& Gilmour Pharmacy \\ Karol Szapel \\ Poznan University of Medical Sciences \\ Marzena Bielas \\ Poznan University of Medical Sciences \\ Jerzy Żabiński \\ Medical University of Warsaw
}

\section{Research Article}

Keywords: pharmacist, pharmaceutical counseling, pharmaceutical care, community pharmacy, inhaler education

Posted Date: April 30th, 2021

DOI: https://doi.org/10.21203/rs.3.rs-453990/v1

License: (c) (i) This work is licensed under a Creative Commons Attribution 4.0 International License. Read Full License 


\section{Abstract}

Background: Following the example of other countries, it is very important to educate patients on the correct use of inhalers by properly trained healthcare professionals, including pharmacists.

Objectives: The aim of the study was to assess the quality and comprehensiveness of professional advice given by pharmacists on the use of inhalers, which was determined by the pharmacists' level of training.

Methods: The study was conducted from June 2019 to March 2020. 150 pharmacists from Poznan and Warsaw (Poland) were involved. Before the study began, the professional education of 240 pharmacists was conducted in Warsaw to implement standard operating procedures. The study used the model of a mystery patient.

Results: The conversation with a trained pharmacist lasted on average 5.5 minutes, with an untrained one - 3.0 minutes. Placebo inhalers were used more often by trained pharmacists during patients' education. $10.3 \%$ of untrained pharmacists did not provide any education. Additionally, untrained employees quality of advice were assessed on an average of 3.5 points, while trained ones -7.6 points.

Conclusions: This study has shown that there is a need for professional training among pharmacists in Poland, which translates into better patient education in the field of inhalation techniques.

\section{Introduction}

Recently, the conventional view of the pharmacist as mainly a person who is dispensing drugs in a pharmacy, has changed significantly in highly developed countries. Undoubtedly, this group of professionals plays an important role in the health care system, and the changes in the perception and understanding of it are more and more noticeable. Pharmacists are involved in the process of health promotion and education during their work [1,2]. Pharmaceutical care is successfully implemented in many countries around the world, such as Great Britain, the Netherlands, Norway, Finland, the United States. Many patients experience multiple benefits from this kind of a service. It can improve the patient's health, as well as the functioning of the entire health care system [3]. Patients suffering from asthma and chronic obstructive pulmonary disease (COPD) have the opportunity to take advantage of inhaler technique education in community pharmacies. It is standard practice for appropriately trained pharmacists to provide consultations regarding prescribed medications and their side effects, self-management of the disease, and instructions on how to use an inhaler. [4].

Asthma and COPD are complex, multifactorial diseases that are often fluctuating in severity over time and require that patients receive support and a comprehensive education, the quality of which can affect the patient's entire life. Good results in treatment depend on the effectiveness of medications and, most importantly, on the correct use of inhalers by patients. Education and training can be effectively delivered by a variety of health professionals, such as physicians, nurses, or pharmacists. Many of the therapeutic problems are caused by an incorrect inhaler technique. Pharmacists are in an excellent position to educate such patients because they are in a highly accessible medical profession $[5,6]$.

Following the example of other countries and the treatment effects they achieved, it is very important to educate patients on how to use inhalers properly. Therefore, the aim of the study was to assess the quality of professional advice given by pharmacists, on the use of inhalers, which was determined by the pharmacists' level of training, in the setting of community pharmacies in Poznan and Warsaw (Poland). Furthermore, the study verified whether the interview conducted by the pharmacist was sufficiently insightful and reliable. The study also assessed how comprehensive and detailed the patient's education was in the technique of inhalation.

\section{Materials And Methods}

The study was conducted from June 2019 to March 2020. The inclusion criteria for selecting the study group was employment in a community pharmacy as a pharmacist. 150 polish pharmacists in Poznan (80, 88.7\% women, $11.3 \%$ men) and Warsaw $(70,90.0 \%$ women, $10.0 \%$ men) were involved in the mystery patient study. Additionally, in 2019-2020 the professional education of 240 pharmacists (86.3\% women, $13.7 \%$ men) was conducted in Warsaw, by an experienced interdisciplinary team consisting of pharmacists and physicians (authors' of the study), in order to increase the knowledge and implement standard operating procedures for patients' inhaler technique education. It was the first practical training on the use of inhalers organized in Poland, in cooperation with the University of Medical Sciences and the Pharmacy Chamber in Warsaw. The training lasted 8 hours and was divided into theoretical (the 
latest recommendations [7]) and practical parts (the use of inhalers and Standard Operating Procedures [8]). The study assessed how the training of pharmacists affects the quality of services and the level of professional pharmaceutical advice they are providing.

150 pharmacists included in the study were divided into 2 groups: trained (43 people; $88.4 \%$ women and $11.6 \%$ men) and untrained (107 people; $89.7 \%$ women and $10.3 \%$ men). The study used the model of a "mystery patient" [9]. This technique assumed that the trained researcher has taken the role of a patient, suffering from asthma in this case. The mystery patient conducted a depth observation each time, assessed the scope of the information and the quality of the advice provided and evaluated the competence of the pharmacist. During the visit in every community pharmacy, the researcher asked the pharmacist to demonstrate how the prescribed inhaler should be used. Each time salbutamol pMDI (Pressurized Metered Dose Inhaler) was used. The conversation with the pharmacist was standardized according to the author's script. After leaving the pharmacy, the particulars concerning the pharmacist's advice and the scope of information provided to the mystery patient about the inhaler technique, was entered into a form based on the World Health Organization protocol [10]. The document was divided into two parts. The first one, pertained to the questions that should be addressed to the patient who is going to be using the inhaler, while they are in the pharmacy. The second part of the form was about the correct inhalation technique using the pMDI. The pharmacist educating the patient was awarded one point for each activity that was performed, from the list containing the description of the correct inhalation technique. It was possible to get the maximum of 9 points for inhalation activities. The document also contained information about the type of education that was provided, e.g. whether the pharmacist performed the training with the use of a placebo inhaler or solely with the use of verbal instruction. Moreover, it contained a subjective assessment of the visit, by the mystery patient, using a point scale from 1 to 10 .

All of the collected data were securely stored in the Department of Pharmaceutical Technology, Pharmacy Practice Division at Poznan University of Medical Sciences. The study was conducted in accordance with the Declaration of Helsinki, and the protocol was approved by the Ethics Committee of Poznan University od Medical Sciences (602/19).

The Statistica PL 12 (StatSoft) package was used to perform the statistical analysis. The correlations between analyzed nominal data were performed by Chi-square test of independence. All statistical analyses were performed at $p<0.05$.

\section{Results}

A properly conducted professional counsel should contain the basic questions about the characteristics of the patient's disease and the circumstances of drug administration. The survey indicated that $55.8 \%$ of trained pharmacists considered it necessary to ask the mystery patient the question "for whom the drug was intended", as opposed to untrained people, where this topic was not mentioned in $90.6 \%$ cases ( $p<0.0001$; Fig. 1). $79.1 \%$ of trained pharmacists checked if the drug had been used previously, but for $74.8 \%$ of the untrained people this issue was irrelevant $(p<0.0001$; Fig. 2$)$. More than half of the trained people $(55.8 \%)$ asked about the reason for prescribing the drug by the physician, while amongst the untrained pharmacists, it was only $8.4 \%(p<0.0001 ;$ Fig. 3$)$. The conversation with trained pharmacists lasted on average 5.5 minutes, and with an untrained person, almost half as long, 3.0 minutes $(p<0.0001$; Fig. 4). Comparing the results of the patient education that was carried out in the community pharmacy by trained and untrained pharmacists in Poland, the differences are clearly noticeable, as shown in Fig. 5. Out of the 9 elements of the correct inhalation technique, the trained pharmacists most frequently paid attention to inserting the mouthpiece in mouth and ensuring a tight seal with mouth $(p<0.0001)$ and pressing the inhaler immediately after starting to inhale through the mouth in order to release a dose of the drug $(p=0.0259)$. They also very often indicated the need to remove the mouthpiece cover $(p<0.0001) .81 .4 \%$ of the trained subjects reported holding the inhaler upright $(p=0.0049)$ and performing a deep exhalation outside the inhaler before inhaling $(p=0.0002)$. Untrained pharmacists conducted significantly less extensive education in the field of inhalation technique. The study noticed that trained pharmacy employees much more often used training inhalers (51.2\% for placebo inhalation) during patient education. Untrained people usually educate the patient solely through verbal instruction $-63.5 \% .10 .3 \%$ of them did not provide any education for the patient (Fig. 6). After the visit, the quality of the advice was assessed comprehensively, on a scale from 1 to 10 . In summary, untrained employees were assessed on an average of 3.5 points, while trained employees -7.6 points $(p<0.0001 ;$ Fig. 7$)$. The summary of the obtained points containing the steps of the correct pMDI inhalation during mystery patient education, indicated that trained pharmacists obtained an average of 6.3 points out of the 9 that were possible, while the untrained ones acquired -4.8 pts $(p<0.0001 ;$ Fig. 8$)$.

\section{Discussion}

The training of pharmacists, supervised by a multidisciplinary team is very important, especially with regard to the correct inhalation technique. It has been confirmed that such activity improves the everyday practice in community pharmacies [10]. Unfortunately, there 
are no suitable training programs in Poland, so the courses that were conducted in this study were pioneering. Their main effect was a more efficient and detailed patient consultation. It is worth mentioning that a pharmacist's empathy and accurate questioning are very important for effective interviewing and providing professional advice for patients in a community pharmacy. Moreover such activity is successfully implemented in many countries and delivers noticeable results in patient care [11]. Providing information on medications, as well as, counseling patients on how to use the inhaler, are the most common elements of the pharmacist's intervention. Furthermore, it is important for pharmacists to focus on improving patient compliance and the patient's understanding of the disease [12].

The study showed that the training of pharmacists contributed to them asking patients more questions to help assess their health status. It seems obvious to ask e.g. for whom the drug is intended. But sometimes this basic question is omitted by some pharmacists [1]. The Polish study by Tomerska-Kowalczyk et al. showed that following appropriate standards for interviewing patients, significantly influenced the number of questions and improved the quality of pharmaceutical consultations [13]. When counseling patients, a pharmacist should make sure that the drug has been used by the patient in the past. This is of particular importance for the further development of the advice. The counsel of a person who does not know how to use a drug will be different than that of a person for whom the drug has already been prescribed previously. Typically, a patient who has just received a new drug needs more time and attention in the pharmacy. However, even patients who demonstrate a sufficient inhalation technique may forget to take their medications regularly. The patients should understand why and how to use the drug correctly[14]. Trained pharmacists are three times more likely to ask the patient if the drug was used before in comparison to untrained ones. A similar study was carried out in Australia, where it was proven that trained pharmacists conducted ample education of patients, and its effects were clear and measurable [15]. Asking the patient about the reason for prescribing the drug, allows for a more in-depth interview. In this way a pharmacist can obtain information about the disease and provide professional advice, individually tailored for each patient. Conducting a sufficient and comprehensive interview about the patient's health and education on the proper use of the inhaler, influences the consultation time. The conversation with the trained pharmacists lasted almost twice as long than with the untrained ones. It is a pharmacist duty to provide information and advice about the effects of drugs, and to make sure that the patient knows and understands the correct inhalation technique $[16,17]$. In the Basheti et al. study it was shown that the majority of patients living in rural areas were unaware of their incorrect inhaler use, but the pharmacist's educational intervention resulted in an improved inhalation technique [18]. It is worth highlighting that patients will search for health information in different sources like the internet or magazines. For this reason, it is extremely important not to leave the patient to fend on their own, but to answer all of their questions and concerns [19].

According to Emeryk et al. effective education should last at least 6-10 minutes for one type of inhaler. All forms and techniques of education in this field are allowed, but a "live" demonstration is the most effective form of inhalation technique education [20]. This study showed that the education of a patient with the use of a demo version of the inhaler is not popular in Poland. More than half of the trained pharmacists used placebo inhalers, which significantly extended the duration of the consultation. This clearly influenced the improvement in the quality of the provided consultation. Unfortunately, it was confirmed that in many community pharmacies there was a lack of placebo inhalers and patients were instructed verbally. It is worth mentioning that demonstration inhalers provide the best way for educating patients, and are considered a standard in community pharmacies in many countries around the world [21, 22].

The role of pharmacists in enhancing the skills of a patient in inhalation techniques is significant. Very often only after this training, patients are able to demonstrate the correct inhaler technique [18]. According to the research of Lindh et al, most of the mistakes made by patients are associated with the type of the device used and an incorrect inhalation technique. The main problems were the lack of slow, deep exhalation before the start of inhalation, and an insufficient breath-hold time after drug application [23, 24, 25]. Based on the conducted study, it was shown that the trained pharmacists were able to conduct a more detailed consultation than untrained ones. Polish pharmacists are burdened with many administrative functions in a community pharmacy. Despite their training, they still did not implement all of the aspects of correct inhalation. It was most likely associated with the lack of sufficient time to conduct a full training for the patient. The most frequently omitted details were: shaking the inhaler well, taking an interval between doses and replacing the dust cap. It is worth mentioning that each element omitted in the inhaler technique may influence the effectiveness of the treatment, therefore additional attention should be paid to providing patients with more detailed and reliable information. Furthermore, the research confirms that carrying out only one training is often insufficient for the patient to repeat all the activities correctly. It has been proven that it is good to reinforce the given advice three times to achieve full inhalation skills [26]. The quality of the provided education by trained pharmacists was much higher in the subjective mystery patient assessment. Moreover, the scores obtained for the individual activities performed during inhalation education were significantly higher for these pharmacists. Publications indicate that qualified pharmacists have been providing that kind of education in many countries for years. A professional pharmacist consultation may bring many positive effects to the patient's pharmacotherapy, therefore their role is extremely significant. [27, 28, 29]. Patients using inhalers require detailed instructions. Pharmacists should consult patients not only when receiving the first inhaler, but also during each

Page $4 / 11$ 
subsequent visit. This provides an ideal opportunity to evaluate the correct use of the device. However, a pharmacist should first undertake appropriate training themselves, in order to be able to educate patients effectively and properly. Research shows that trained pharmacists get practical skills and broaden their knowledge, which has a huge impact on improving asthma and COPD control in patients. Without specific training, they will not have the required skills to provide an effective consultation to patients $[7,30]$.

Diseases of the respiratory system are a serious health problem, and asthma or COPD are classified in the categories of civilization diseases [7, 31]. The health system in Poland is increasingly struggling with the underdiagnosis of these kinds of patients, who instead of specialists, seek information on the internet, especially during the COVID-19 pandemic, when access to physicians is limited. Poor access to professional care is associated with a high risk of underdiagnosis and perilous therapeutic decisions [32]. The pharmacists definitely play an important role in patient health care. While other specialists closed their doors to patients during the pandemic, community pharmacies remained open despite the risks. Pharmacists are now the most accessible health professionals [33]. Unfortunately, unlike in many countries where pharmaceutical care has been functioning successfully for many years, in Poland we do not have official guidelines for professional pharmacological consultations [34]. It should be emphasized that pharmacists continue to develop their skills constantly. Cyclical training has a positive impact, because pharmacists are able to refresh their knowledge and find motivation. A systematic review of effective inhalation techniques has shown that the effect diminishes over time, therefore it is important to conduct periodic training, not only for the benefit of patients, but also for pharmacists [35]. Pharmacy students also have great potential. During the university classes, they should attend as many practical exercises as possible, for example with the use of the Simulated Patients, which have shown to have a significant influence on the development of adequate skills [36]. It is worth investing in the education of students and pharmacists, because it has a great impact on the effectiveness of a patient's pharmacotherapy, and significantly reduces unnecessary expenses of health care. The investment in education and training of pharmacists has shown to improve the health of patients with chronic diseases and constitutes a cost-effective alternative [37].

\section{Conclusions}

Pharmacists provide many benefits to patients by devoting sufficient time to define the problem and provide professional advice. In Poland, there is a great need to create appropriate procedures for counseling. This study has shown the need for professional training among pharmacists, which translates into better patient education. It has many positive outcomes for patients and the entire health system. Standard Operating Procedures, which are applied for a long time in many countries, should constitute a specific guideline for its implementation in Polish community pharmacies.

\section{Declarations}

\section{Ethics approval and consent to participate:}

The study was conducted in accordance with the Declaration of Helsinki, and the protocol was approved by the Ethics Committee of Poznan University od Medical Sciences (602/19, date of approval: 15.05.2019)

All pharmacists were informed during the training about the potential visits of mystery patient in their community pharmacy and possibility of inclusion in the research. All participants were clearly familiar with their role in this study (purpose, procedures, risks, benefits etc.) and had the chance to ask clarifying questions if necessary. People who did not consent were excluded from the study. The pharmacists provided verbal informed consent to participate in the study also after mystery patient contact, which results from the research methodology.

Consent for publication: Not applicable.

Availability of data and materials: The datasets used and/or analysed during the current study are available from the corresponding author on reasonable request.

Competing interests: The authors declare that they have no competing interests.

Funding: This research was funded by Poznan University of Medical Sciences, grant number 502-01-03314429-03439.

Authors' contributions: Conceptualization, M.W.N., M.B., J.Ż., P.D. ; methodology, M.W.N.; software, M.M..; validation, M.W.N., P.T. formal analysis, M.W.N., P.T., W.G. M.M.; investigation, M.W.N., P.T., B.P. resources, M.W.N.; data curation, M.W.N.; writing-original draft 
preparation, M.W.N., W.G., P.T.; writing-review and editing, J.Ż., A.B., K.S., B.P., M.BI., P.D., M.B.; visualization, M.W.N., W.G., P.T.; supervision, M.W.N., M.B., P.D., J.Ż.; project administration, M.W.N. funding acquisition, M.W.N.

Acknowledgments: Special thanks to Prof. Janina Lulek PhD, MSc (Head of the Department of Pharmaceutical Technology) for support and motivation

Conflicts of Interest: The authors declare no conflict of interest. The funder had no role in the design of the study; in the collection, analyses, or interpretation of data; in the writing of the manuscript, or in the decision to publish the results.

\section{References}

1. Waszyk-Nowaczyk, M.; Bajsert, A. Profesjonalne doradztwo w aptekach ogólnodostępnych - analiza wybranych krajów. Pol Prz Nauk Zdr. 2018, 3, 301-305.

2. Pharmaceutical Group of European Union PGEU. Annual Report, 2019. Available online: https://www.pgeu.eu/wpcontent/uploads/2020/03/200402-PGEU-Annual-Report-2019.pdf; 2019 (accessed on 05.03.2021).

3. Alves da Costa, F. Pharmaceutical Care in Europe. In The Pharmacist Guide to Implementing Pharmaceutical Care, 1st ed.; Alves da Costa F., Foppe van Mil, J.W; Alvarez-Risco, A., Eds.; Springer: Cham, Switzerland, 2019; Part III, Chap. 14, pp. 159-171.

4. Schwartzberg, E.; Nathan, J.P.; Avron, S.; Marom, E. Clinical and other specialty services offered by pharmacists in the community: the international arena and Israel. Isr J Health Policy Res. 2018, 7(59), 1-11.

5. Lampkin, S.J.; Maslouski, C.A.; Maish, W.A.; John, B.M. Asthma Review for Pharmacists Providing Asthma Education. J Pediatr Pharmacol Ther. 2016, 21(5), 444-471.

6. Garcia-Cardenas, V.; Armour, C.; Benrimoj, S.I.; Martinez-Martinez, F.; Rotta, I.; Fernandez-Llimos, F. Pharmacists' interventions on clinical asthma outcomes: a systematic review. Eur Respir J. 2016, 47(4), 1134-1143.

7. Global Strategy for Asthma Management and Prevention. Report, 2020. Available online: https://ginasthma.org/wpcontent/uploads/2020/04/GINA-2020-full-report_final-_wms.pdf (accessed on 05.03.2021).

8. Waszyk-Nowaczyk, M.; Żabiński, J.; Plewka B. Astma i POChP. Profesjonalne wsparcie pacjenta w aptece. Obsługa inhalatorów podręczny poradnik farmaceuty. Biul. Inf. Okręg. Izby Aptek. 2019, 3(1), 1-48.

9. Jesson, J.K. Demystifying the mystery shopper: is it a justifiable research method? Pharm J. 2004, 272, 615-617.

10. World Health Organization. Regional Office for Europe \& EuroPharm Forum. (1998). Pharmacy-based asthma services: protocol and guidelines. Copenhagen: WHO Regional Office for Europe. Available online: https://apps.who.int/iris/handle/10665/108251 (accessed on 21.02.2021).

11. Hussain, F.N.; Paravattil, B. Assessment of Educational Inhaler Technique Interventions Among Community Pharmacists: A Systematic Review. Integr Pharm Res Pract. 2020, 9, 23-31.

12. Bridgeman, M.B.; Wilken, L.A. Essential Role of Pharmacists in Asthma Care and Management. J Pharm Pract. 2020, 34(1), 149162.

13. Tomerska-Kowalczyk, E.; Skowron, A.; Brandys, J. Wpływ Standardowych Procedur Operacyjnych na proces udzie-lania informacji pacjentom podczas realizacji recept lekarskich w aptekach ogólnodostępnych. Farm Pol. 2014, 70, 452-459.

14. Asthma: the role of practice pharmacist, article by Garry McDonald. Available online: https://www.guidelinesinpractice.co.uk/respiratory/asthma-the-role-of-the-practice-pharmacist/454617.article (accessed on 22.02.2021).

15. Saini, B.; Krass, I.; Smith, L.; Bosnic-Anticevich, S.; Armour, C. Role of community pharmacists in asthma - Australian research highlighting pathways for future primary care models. Australas Med J. 2011, 4(4), 190-200.

16. Internetowy System Ustaw Prawnych: Ustawa z dnia 19 kwietnia 1991 r. o izbach aptekarskich (Dz.U. 1991 Nr 41 poz. 179) Available online: http://prawo.sejm.gov.pl/isap.nsf/download.xsp/WDU19910410179/U/D19910179 Lj.pdf (accessed on 05.05.2020).

17. Merks, P.; Bryła, A.; Harężlak, T.; Chmielewska-Ignatowicz, T.; Swieczkowski, D.; Krysiński, J.; Jaguszewski, M. Ocena jakości pracy farmaceutów w aptekach ogólnodostępnych na terenie Polski. Farm Pol. 2019, 75(5), 233-237.

18. Basheti, I.A.; Salhi, Y.B.; Basheti, M.M.; Hamadi, S.A.; Al-Qerem, W. Role of the pharmacist in improving inhaler technique and asthma management in rural areas in Jordan. Clin Pharmacol. 2019, 11, 103-116. 
19. Pasztak-Opiłka, A. Wybrane aspekty funkcjonowania współczesnego człowieka w obszarze zdrowia i choroby. In: Psychospołeczne i środowiskowe konteksty zdrowia i choroby, 1st ed.; Borzucka-Sitkiewicz, K., Ed.; Wydawnictwo Uni-wersytetu Śląskiego, Katowice, Poland, 2016; pp. 101-124.

20. Emeryk, A.; Bodajko-Grochowska, A.; Bartkowiak-Emeryk, M. Inhalatory suchego proszku - jak ważna jest edukacja chorego. Alergia. $2013,3,17-21$.

21. National Health Servise Scotland. Community Pharmacy Asthma Service Level Specification, 2015. Available online: https://www.communitypharmacy.scot.nhs.uk/media/1719/les_asthma_jan_2015_nhs_tayside_community_pharmacy_160115.pdf (accessed on 05.03.2021).

22. National Asthma Council Australia. Information paper for health professionals: Inhaler technique in adults with asthma or COPD, 2008. Available online: https://www.hps.com.au/wp-content/uploads/2017/01/NACA-Inhaler-technique- in-adults-with-asthma-orCOPD.pdf (accessed on 05.03.2021).

23. Lindh, A.; Theander, K.; Arne, M.; Lisspers, K.; Lundh, L.; Sandelowsky, H.; Ställberg, B.; Westerdahl, E.; Zakrisson, A.B. Errors in inhaler use related to devices and to inhalation technique among patients with chronic obstructive pulmonary disease in primary health care. Nurs Open. 2019, 6(4), 1519-1527.

24. Cho-Reyes, S.; Celli, B.R.; Dembek, C.; Yeh, K.; Navaie, M. Inhalation Technique Errors with Metered-Dose Inhalers Among Patients with Obstructive Lung Diseases: A Systematic Review and Meta-Analysis of U.S. Studies. Chronic Obstr Pulm Dis. 2019, 6(3), 267280.

25. Sanchis, J.; Gich, I.; Pedersen, S. Systematic Review of Errors in Inhaler Use: Has Patient Technique Improved Over Time? Chest. 2016, 150(2), 394-406.

26. Takaku, Y.; Kurashima, K.; Ohta, C.; Ishiguro, T.; Kagiyama, N.; Yanagisawa, T.; Takayanagi, N. How many instructions are required to correct inhalation errors in patients with asthma and chronic obstructive pulmonary disease? Respir Med. 2017, 123, 110-115.

27. Asthma UK and British Lung Foundation Partnership, 2020. Available online: https://www.asthma.org.uk/advice/manage-yourasthma/pharmacist/ (accessed on 05.03.2021).

28. Bouwmeester, C.; Kraft, J.; Bungay, K.M. Optimizing inhaler use by pharmacist- provided education to communi-ty-dwelling elderly. Respir Med. 2015, 109, 1363-1368.

29. Ali, A.; Pena, S.G.; Huggins, C.; Lugo, F.; Khaja, M.; Diaz-Fuentes, G. Impact of Group Asthma Education on Asthma Control and Emergency Room Visits in an Underserved New York Community. Can Respir J. 2019, 2019, 1-7.

30. Basheti, I.A.; Armour, C.L.; Reddel, H.K.; Bosnic-Anticevich, S.Z. Long-Term Maintenance of Pharmacists' Inhaler Technique Demonstration Skills. Am J Pharm Educ. 2009, 73(2), 32.

31. Global Strategy for the Diagnosis, Management, and Prevention of Chronic Obstructive Pulmonary Disease. Report, 2020. Available online: https://goldcopd.org/wp-content/uploads/2019/12/GOLD-2020-FINAL-ver1.2-03Dec19_WMV.pdf (accessed on 05.03.2021).

32. NFZ o zdrowiu: astma. Raport, 2020. Available online: https://www.nia.org.pl/wpcontent/uploads/2020/05/nfz_o_zdrowiu_astma.pdf (accessed on 05.03.2021).

33. Elbeddini, A.; Prabaharan, T.; Almasalkhi, S.; Tran, C. Pharmacists and COVID-19. J Pharm Policy Pract. $2020 ; 13,36$.

34. National Pharmacy Association. Standard Operating Procedures, 2020. Available online: https://www.npa.co.uk/services/essentialsops-standardoperatingprocedures (accessed on 05.03.2021).

35. Makhinova, T.; Walker, B.L.; Gukert, M.; Kalvi, L.; Guirguis, L.M. Checking Inhaler Technique in the Community Pharmacy: Predictors of Critical Errors. Pharmacy. 2020, 8(1), 6.

36. Cerbin-Koczorowska, M.; Przymuszala, P.; Waszyk- Nowaczyk, M.; Plewka, B.; Marciniak, R. The Need for Simulated Patient Method Implementation in Pharmaceutical Education in Poland. Indian J Pharm Edu Res. 2020, 54(4), 875-80

37. Dalton, K.; Byrne, S. Role of the pharmacist in reducing healthcare costs: current insights. Integr Pharm Res Pract. $2017,6,37-46$.

\section{Figures}




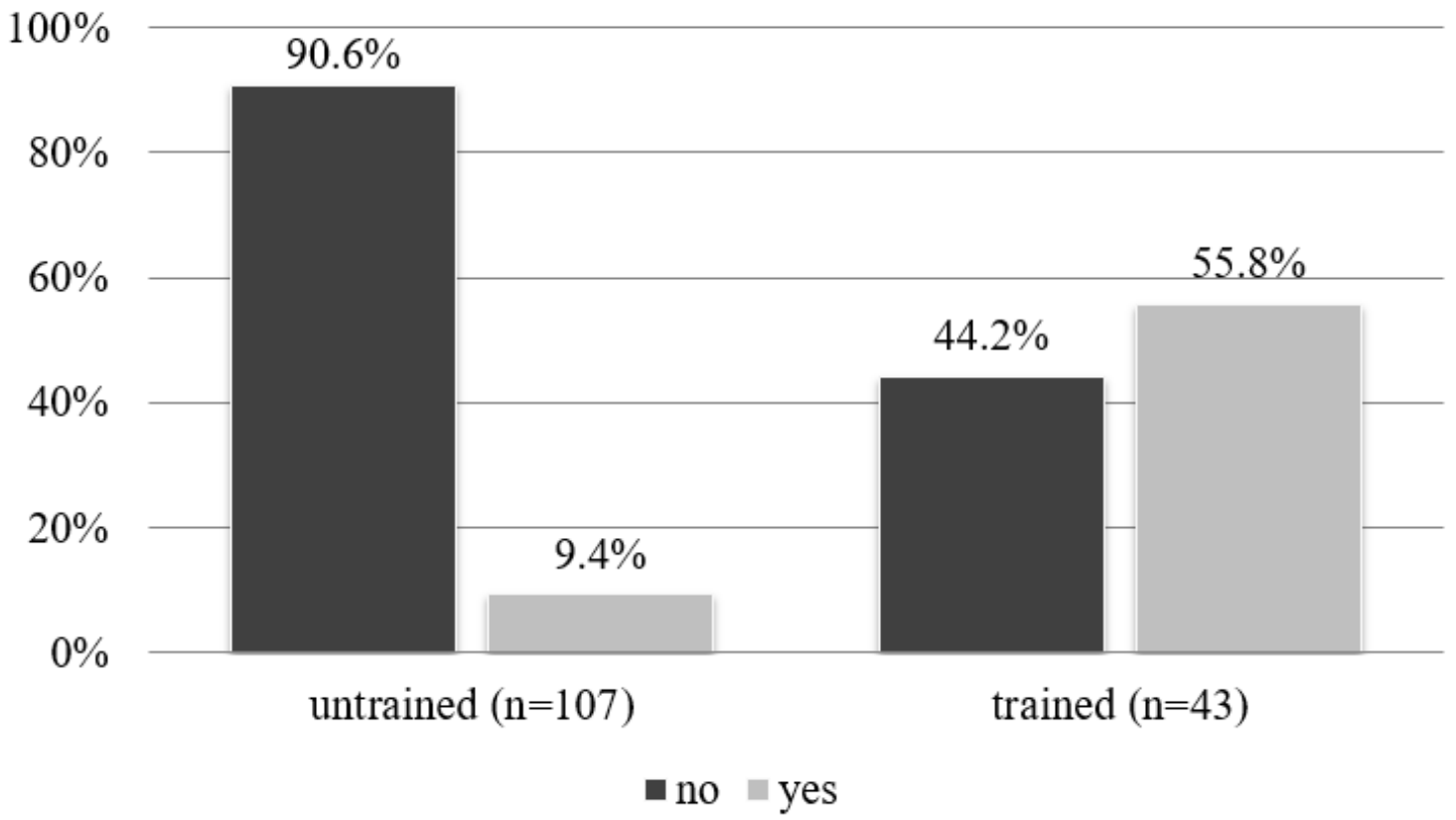

Figure 1

Question asked about the person for whom the drug was prescribed, determined by the pharmacist's level of training $\left(n=150, p<0.0001^{\star}\right)$ * statistically significant results at $p<0.05$

$100 \%$

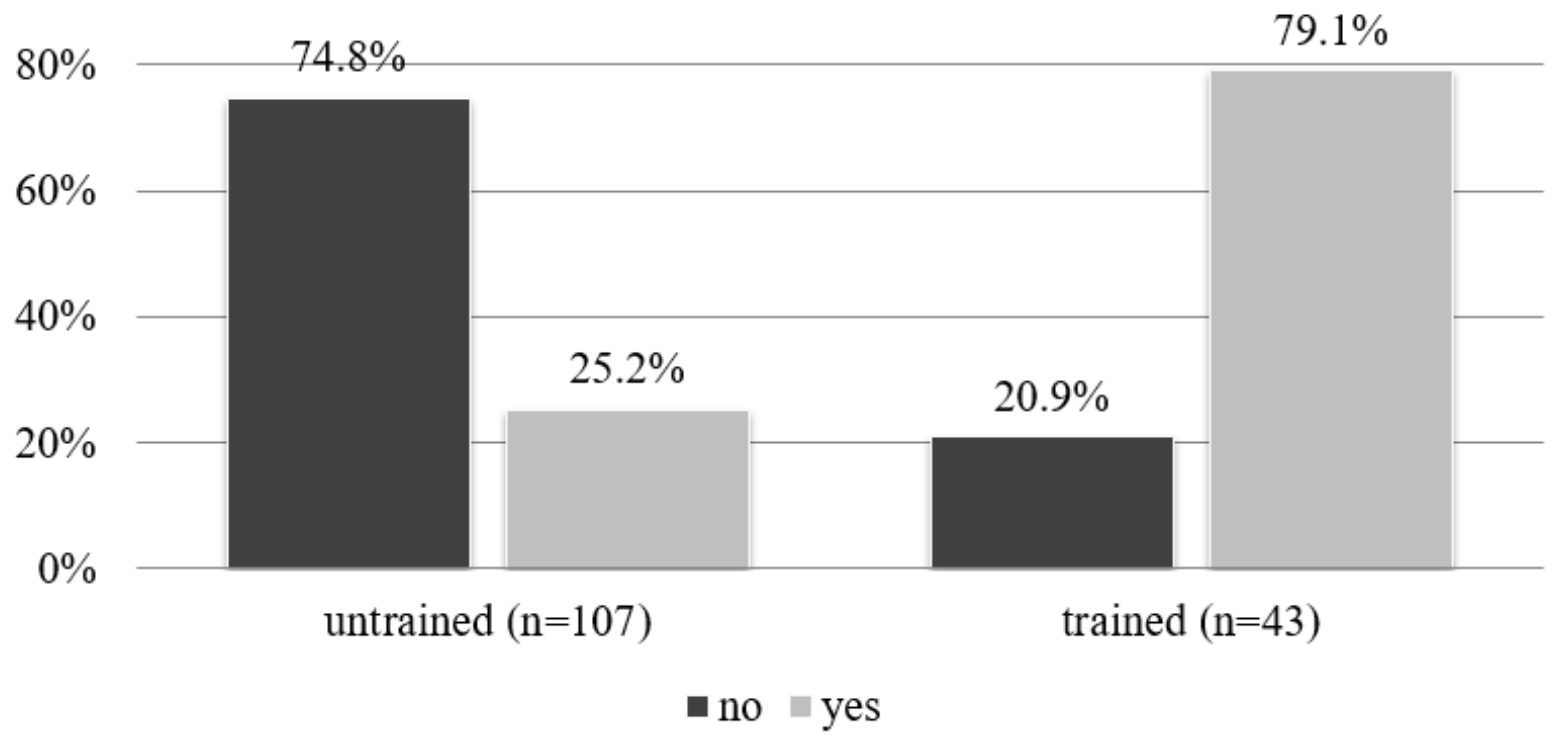

Figure 2

Question asked about prior use of the drug by the patient, determined by the pharmacist's level of training. ( $\left.n=150, p<0.0001^{*}\right)$ * statistically significant results at $\mathrm{p}<0.05$ 


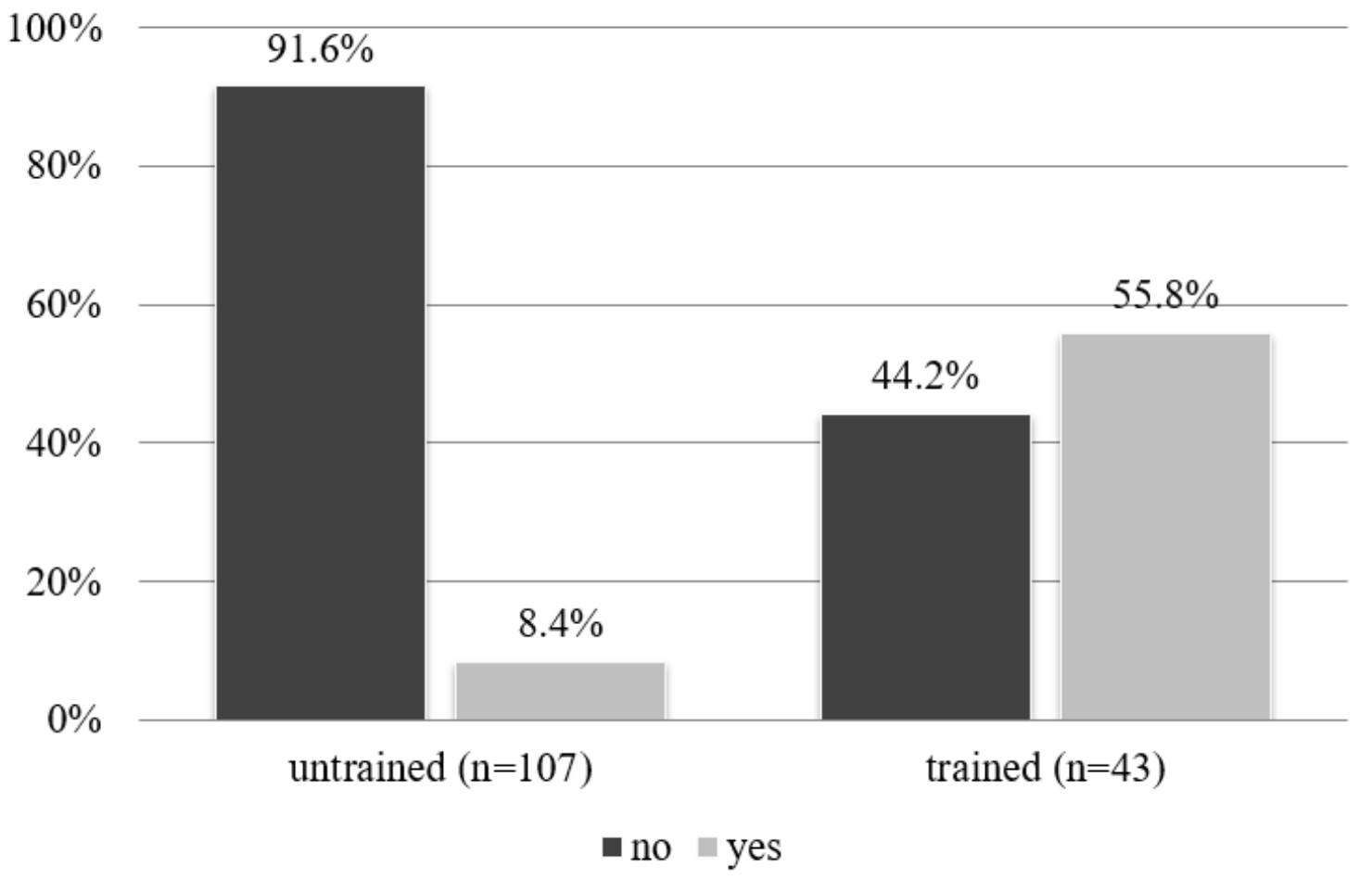

\section{Figure 3}

Question asked about the reason for prescribing the drug by physician, determined by the pharmacist's level of training ( $n=150$, $p<0.0001 *) *$ statistically significant results at $p<0.05$

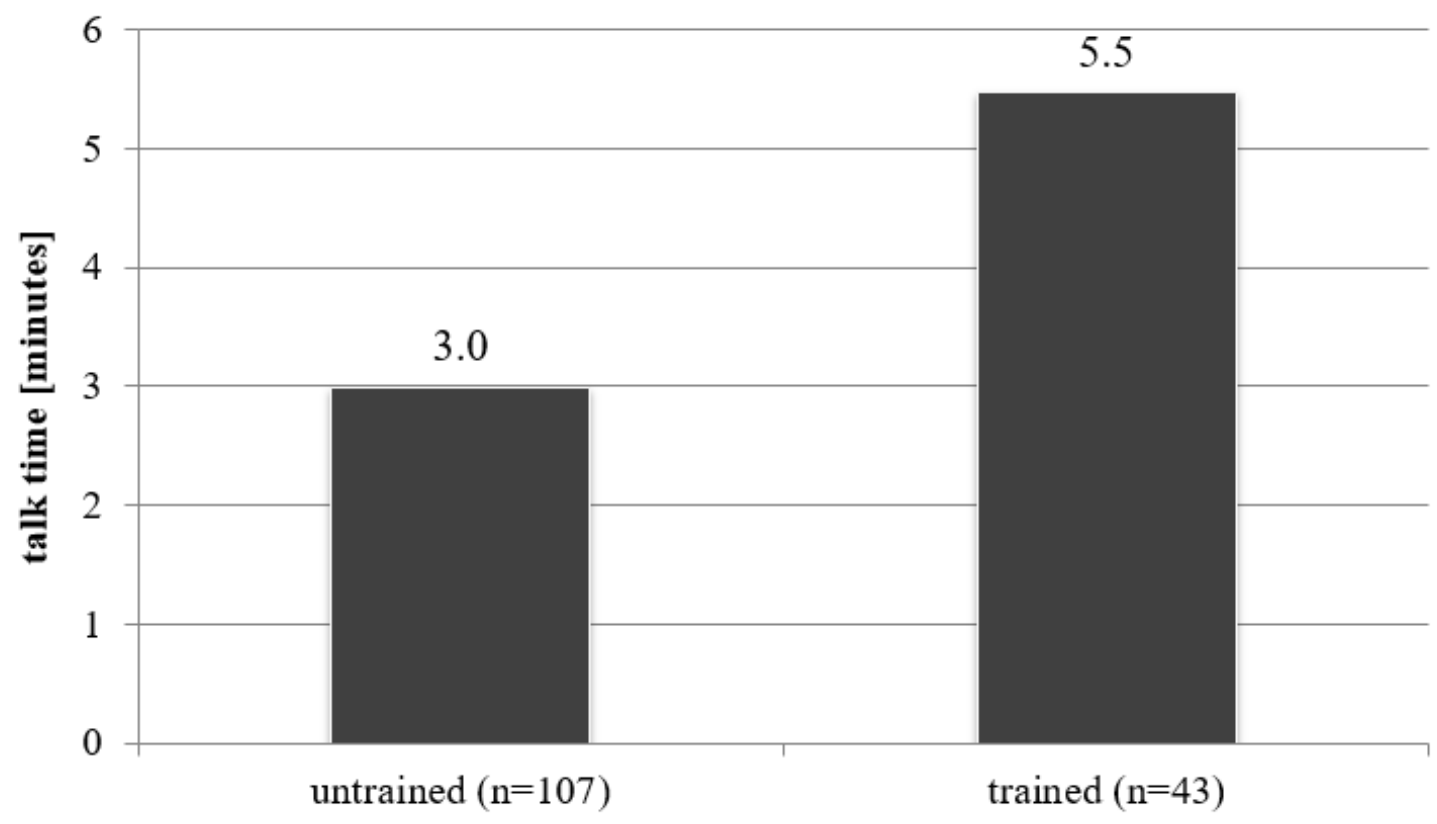

\section{Figure 4}

The average duration of a consultation, determined by the pharmacist's level of training $(n=150, p<0.0001 *)$ * statistically significant results at $p<0.05$ 


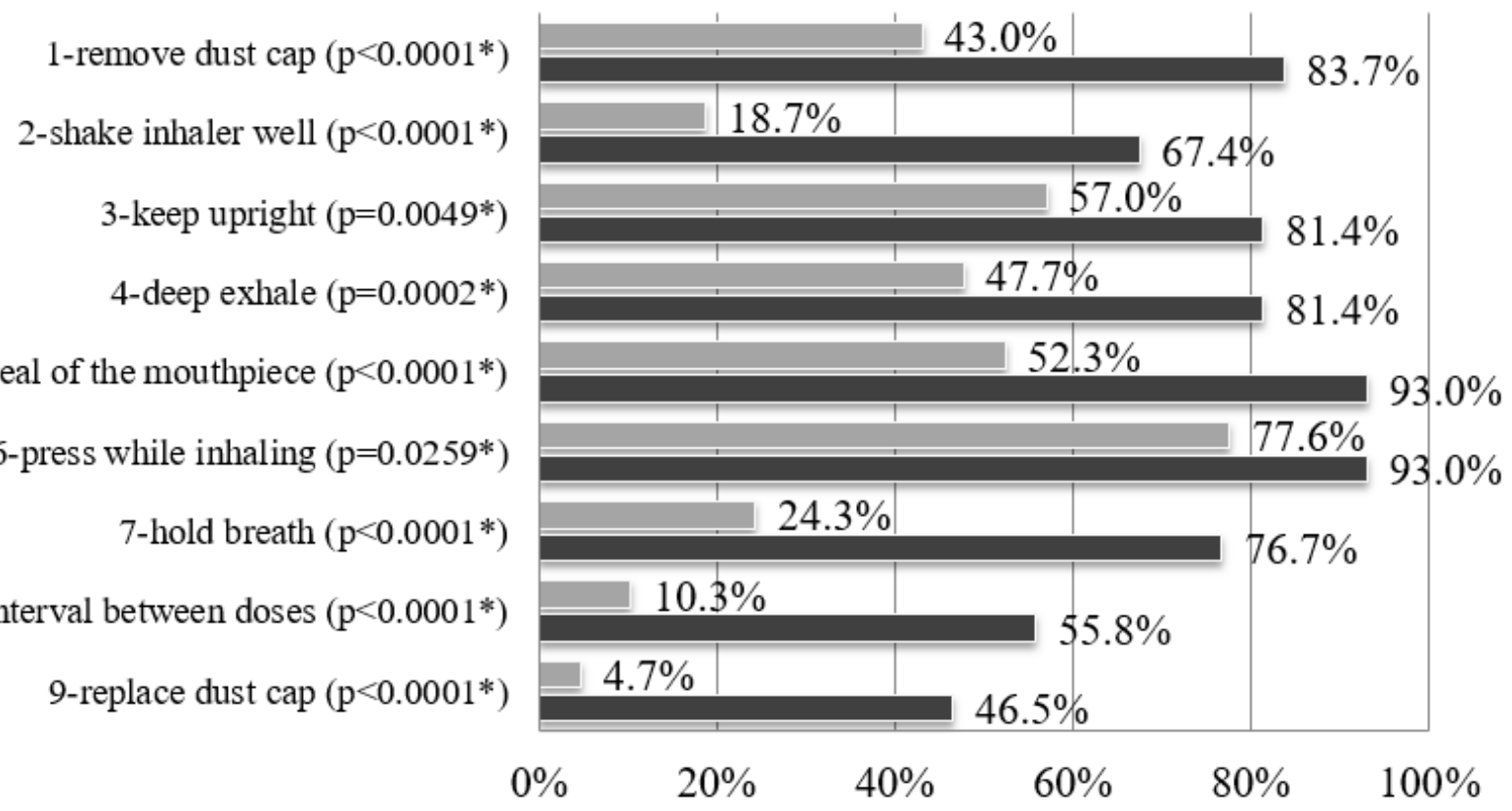

untrained $(\mathrm{n}=107) \quad$ - trained $(\mathrm{n}=43)$

\section{Figure 5}

Information about the inhalation technique during patient education, determined by the pharmacist's level of training $(n=150)$ * statistically significant results at $p<0.05$

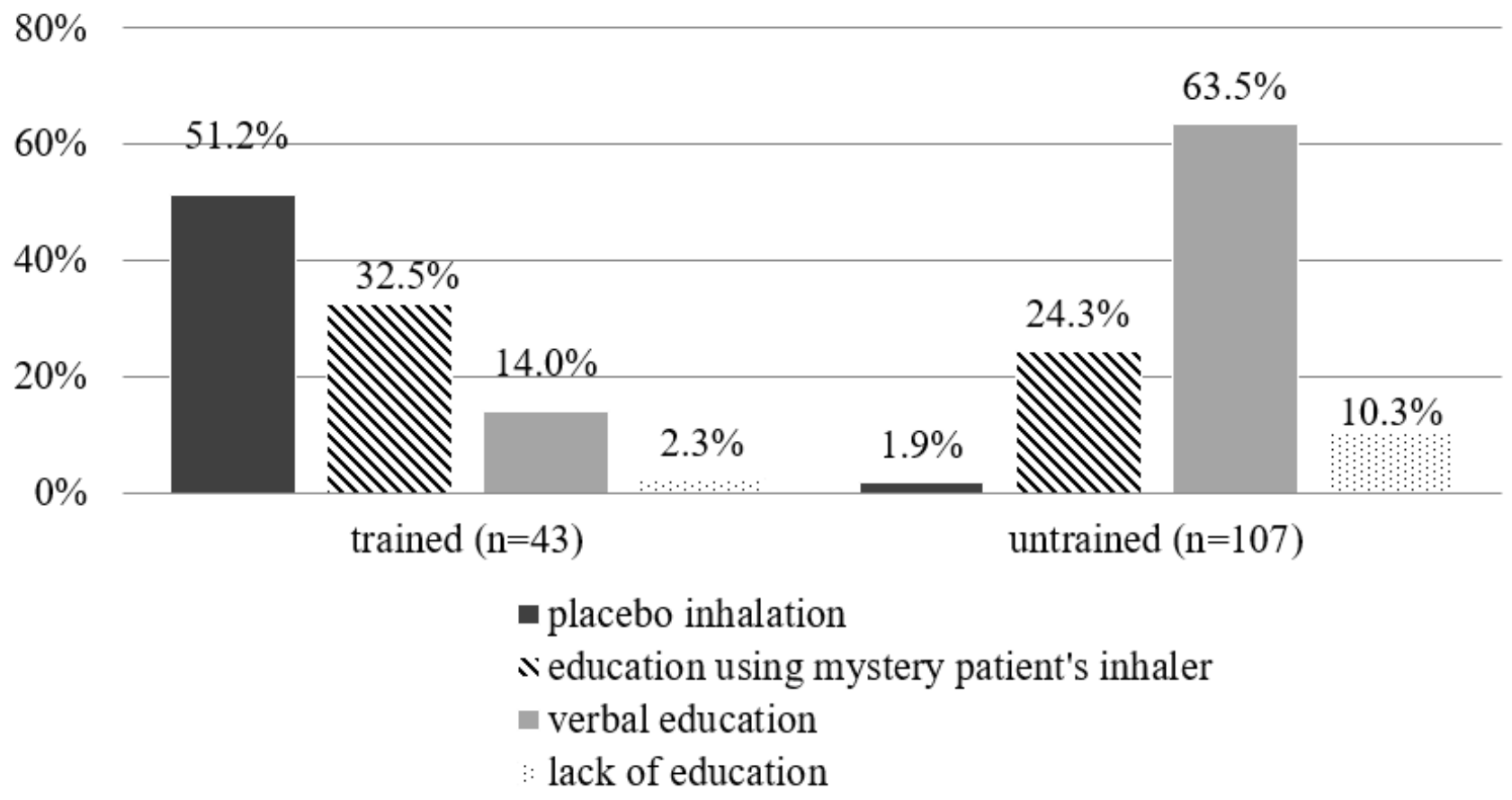

Figure 6

Type of conducted education, determined by the pharmacist's level of training $(n=150, p<0.0001 *)$ * statistically significant results at $p<0.05$ 


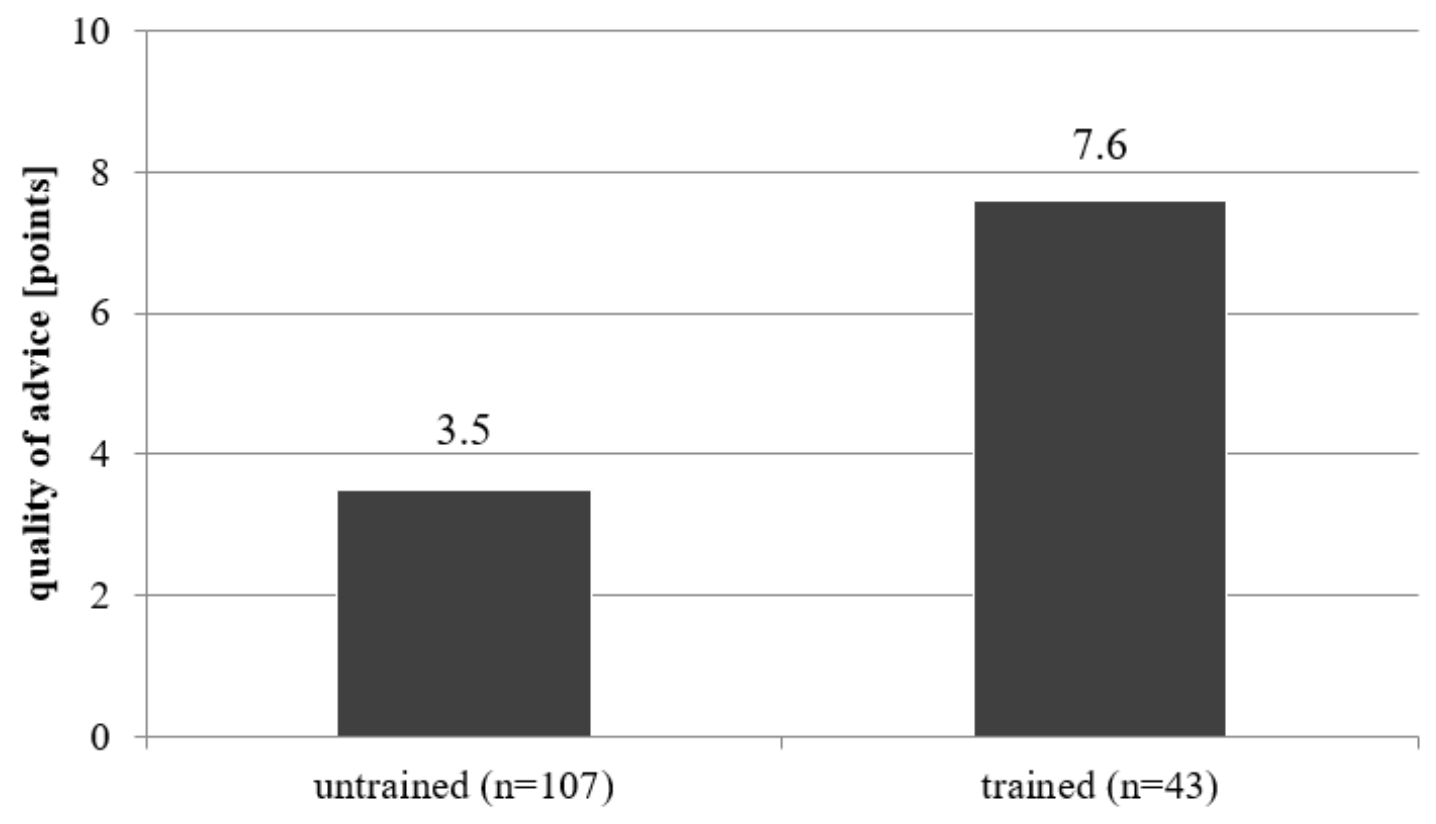

\section{Figure 7}

Average quality of advice on a scale from 1-10, determined by the pharmacist's level of training $(n=150, p<0.0001 *)$ * statistically significant results at $p<0.05$

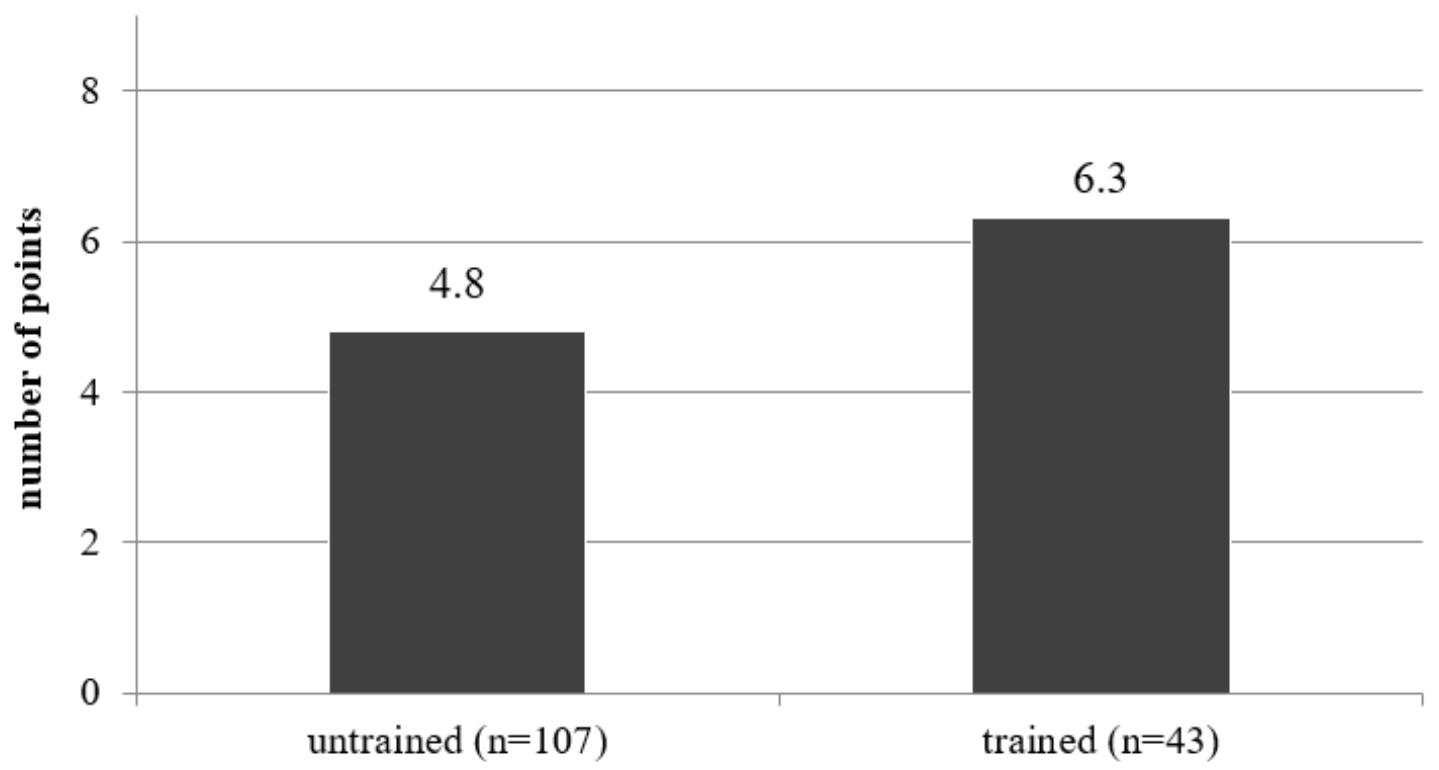

\section{Figure 8}

The average number of points obtained by educators in the field of inhalation technique, determined by the pharmacist's level of training $(n=150 ; p<0.0001 *)$ * statistically significant results at $p<0.05$ 